\title{
Copper and tin isotopic analysis of ancient bronzes for archaeological investigation: development and validation of a suitable analytical methodology
}

\author{
Eleonora Balliana • Maite Aramendía • Martin Resano • \\ Carlo Barbante • Frank Vanhaecke \\ Received: 29 August 2012 /Revised: 30 October 2012 /Accepted: 31 October 2012 / Published online: 22 November 2012 \\ (C) Springer-Verlag Berlin Heidelberg 2012
}

\begin{abstract}
Although in many cases $\mathrm{Pb}$ isotopic analysis can be relied on for provenance determination of ancient bronzes, sometimes the use of "non-traditional" isotopic systems, such as those of $\mathrm{Cu}$ and $\mathrm{Sn}$, is required. The work reported on in this paper aimed at revising the methodology for $\mathrm{Cu}$ and $\mathrm{Sn}$ isotope ratio measurements in archaeological bronzes via optimization of the analytical procedures in terms of sample pre-treatment, measurement protocol, precision, and analytical uncertainty. For $\mathrm{Cu}$ isotopic analysis, both $\mathrm{Zn}$ and $\mathrm{Ni}$ were investigated for their merit as internal standard (IS) relied on for mass bias correction. The use of $\mathrm{Ni}$ as IS seems to be the most robust approach as $\mathrm{Ni}$ is less prone to contamination, has a lower abundance in bronzes and an ionization potential similar to that of $\mathrm{Cu}$, and provides slightly better reproducibility values when applied to
\end{abstract}

Published in the topical collection Isotope Ratio Measurements: New Developments and Applications with guest editors Klaus G. Heumann and Torsten C. Schmidt.

Electronic supplementary material The online version of this article (doi:10.1007/s00216-012-6542-1) contains supplementary material, which is available to authorized users.

E. Balliana $\cdot$ F. Vanhaecke $(\bowtie)$

Department of Analytical Chemistry, Ghent University,

Krijgslaan 281-S12,

9000 Ghent, Belgium

e-mail: frank.vanhaecke@UGent.be

M. Aramendía

Centro Universitario de la Defensa, Carretera de Huesca s/n,

50090 Zaragoza, Spain

M. Aramendía $\cdot$ M. Resano

Department of Analytical Chemistry, University of Zaragoza,

Calle Pedro Cerbuna 12,

50009 Zaragoza, Spain

E. Balliana $\cdot$ C. Barbante

Department of Environmental Sciences, Informatics and Statistics,

Ca' Foscari University of Venice, Calle Larga S. Marta 2137,

30123 Venice, Italy
NIST SRM $976 \mathrm{Cu}$ isotopic reference material. The possibility of carrying out direct isotopic analysis without prior $\mathrm{Cu}$ isolation (with AG-MP-1 anion exchange resin) was investigated by analysis of CRM IARM 91D bronze reference material, synthetic solutions, and archaeological bronzes. Both procedures ( $\mathrm{Cu}$ isolation/no $\mathrm{Cu}$ isolation) provide similar $\delta^{65} \mathrm{Cu}$ results with similar uncertainty budgets in all cases $( \pm 0.02-0.04$ per mil in delta units, $k=2, n=$ 4). Direct isotopic analysis of $\mathrm{Cu}$ therefore seems feasible, without evidence of spectral interference or matrix-induced effect on the extent of mass bias. For Sn, a separation protocol relying on TRU-Spec anion exchange resin was optimized, providing a recovery close to $100 \%$ without oncolumn fractionation. $\mathrm{Cu}$ was recovered quantitatively together with the bronze matrix with this isolation protocol. Isotopic analysis of this $\mathrm{Cu}$ fraction provides $\delta^{65} \mathrm{Cu}$ results similar to those obtained upon isolation using AG-MP-1 resin. This means that $\mathrm{Cu}$ and $\mathrm{Sn}$ isotopic analysis of bronze alloys can therefore be carried out after a single chromatographic separation using TRU-Spec resin. Tin isotopic analysis was performed relying on $\mathrm{Sb}$ as an internal standard used for mass bias correction. The reproducibility over a period of 1 month $(n=42)$ for the mass bias-corrected $\mathrm{Sn}$ isotope ratios is in the range of $0.06-0.16$ per mil $(2 \mathrm{~s})$, for all the ratios monitored.

Keywords Copper isotopic analysis - Tin isotopic analysis . Multi-collector ICP-mass spectrometry · Archaeological bronze $\cdot$ Archaeometry

\section{Introduction}

Nowadays, archaeology and analytical chemistry form an essential tandem for investigating the past. Isotopic analysis, in particular, is a very powerful tool for discrimination purposes and for provenance studies and is therefore 
presently replacing and/or complementing the more traditional multi-element analysis in the context of archaeometry [1-3]. Owing to the introduction of multi-collector inductively coupled plasma-mass spectrometry (MC-ICP-MS) instruments, the interest for isotopic analysis has grown considerably, not only for elements with radiogenic nuclides (such as $\mathrm{Pb}, \mathrm{Sr}$, or $\mathrm{Nd}$ ) [3], for which larger isotopic variations are observed in nature, but also for "non-traditional" stable isotopic systems (such as those of $\mathrm{Cu}$ or $\mathrm{Sn}$ ), showing smaller variation, mainly due to mass-dependent isotope fractionation [4-8]. At this point, systematic studies are still needed to fully assess the possibilities of these nontraditional isotopic systems in the field of archaeometry, starting from optimization of the analytical methodology, at a later stage deployed for trying to relate the isotopic information to, e.g., geographical origin of raw materials, mining activities, manufacturing technology, and/or trade routes $[9,10]$.

To fully understand the steps that need to be taken to be able to use isotopic information in the context of archaeometry, one can refer to $\mathrm{Pb}$ as an illustrative example. In fact, $\mathrm{Pb}$ is the element most commonly used for this purpose and has been successfully applied to many ancient artifacts for obtaining meaningful archeological conclusions [11-14]. Historically, $\mathrm{Pb}$ was among the first ore-extracted metals, and, because of this, ore-derived $\mathrm{Pb}$ is found abundantly in the composition of many ancient artifacts at many archaeological sites. $\mathrm{Pb}$ has four stable isotopes, three of which are radiogenic, which results in a wide range of natural variation in the isotopic composition of this element. Moreover, the isotopic composition of $\mathrm{Pb}$ does not seem to be measurably affected by isotope fractionation during ore processing and manufacturing of the objects. This fact renders $\mathrm{Pb}$ isotopic analysis a powerful tool for provenance studies, founded on the assumption that ore deposits can often be distinguished from one another based on their $\mathrm{Pb}$ isotopic signature $[3$, 14-18]. Ideally, the cluster of isotope ratios for a given deposit is visualized on a bivariate plot (e.g., ${ }^{207} \mathrm{~Pb} /{ }^{204} \mathrm{~Pb}$ versus ${ }^{206} \mathrm{~Pb} /{ }^{204} \mathrm{~Pb}$ ) and provides a unique fingerprint for that deposit. Archaeologists can then match the isotope ratios of individual archaeological artifacts to the fingerprints of their parent ore source, such that archaeological conclusions can be drawn [18-20]. In some other instances, provenancing to the original ores is not aimed at, and lead isotopic analysis is used to fingerprint artifacts from a given workshop, period, or any other possible classification and to distinguish or discriminate them from one other $[13,17$, 21-24].

Unfortunately, in some cases, serious limitations affect $\mathrm{Pb}$ isotopic analysis. For ore provenancing, e.g., overlapping fingerprints of two or more ores often occur, and the possibility that ores and/or recycled materials from different sources have been used for the production of a given object always exists. In such situations, the combined study of different isotopic systems could be helpful for resolving the ambiguity [3]. In this context, the use of the $\mathrm{Cu}$ isotope ratio complementing $\mathrm{Pb}$ isotopic information for provenancing of $\mathrm{Cu}$ ores used in ancient metallic artifacts has already been proposed as a potential tool in this direction, although further studies are needed to ascertain the viability of this option [3, 25-28].

In some other cases, $\mathrm{Pb}$ cannot be used as a valid tracer, either because the amount of $\mathrm{Pb}$ in the final artifact is not high enough to carry out isotopic analysis of sufficient quality or because the $\mathrm{Pb}$ in the artifact is not linked to a particular ore, thus precluding its use for provenancing [7, 29]. These circumstances, for instance, occur in the study of ancient bronze samples with very low levels of $\mathrm{Pb}$. Exploring the possibility of using $\mathrm{Cu}$ and $\mathrm{Sn}$ isotopic information for the study of such artifacts would obviously be interesting, and this is one of the goals of our investigation.

Considering the lack of information on this aspect, further studies have to be conducted for confirming the fact that the $\mathrm{Cu}$ and $\mathrm{Sn}$ isotopic signature of a given bronze artifact can be traced to the original ore or, at least, that a clear fingerprint can be obtained, allowing to distinguish between, e.g., different manufacturing workshops or periods. At a later stage, and if the first hypothesis is confirmed, extensive isotopic databases need to be built for provenancing studies. Before starting such an ambitious project, however, the development of an analytical methodology for determining $\mathrm{Cu}$ and $\mathrm{Sn}$ isotope ratios in archaeological bronze samples with the lowest uncertainty values possible needs to be carefully considered. Currently, the few papers available dealing with $\mathrm{Cu}$ and $\mathrm{Sn}$ isotopic analysis in the context of archaeometry are mainly focused on the interpretation of results $[7,25,27,28,30]$, while little attention is paid to the analytical methodology itself, which, in fact, could be the clue to obtaining meaningful results. These papers suggest that isotopic analysis of $\mathrm{Cu}$ and $\mathrm{Sn}$ could be used for provenancing purposes but report a rather narrow range of isotopic variation (a few per mil delta units in the best case) for these two elements in different ores [4-6, $8,16,25,26,30,31]$. Data are still too scarce as to be conclusive, but it seems clear that optimization of the analytical methodology may be much more crucial in the case of $\mathrm{Cu}$ and $\mathrm{Sn}$ than in the case of $\mathrm{Pb}$, for which isotopic variations up to $5 \%$ can be observed. The aim of the present work is to revise the methodology for $\mathrm{Cu}$ and $\mathrm{Sn}$ isotope ratio measurements in ancient bronzes with the purpose of: (1) optimizing the analytical methodology for both $\mathrm{Cu}$ and $\mathrm{Sn}$ in terms of sample pre-treatment (digestion and, especially, target element isolation) and measurement protocol by means of MC-ICP-MS, with special attention to mass bias correction; (2) assessing the results obtained in terms of internal precision and reproducibility; and (3) applying the 
protocol developed to some pre-Roman bronze utensils originating from northern Spain.

\section{Experimental section}

Standards and reagents

All sample pre-treatment procedures (digestion, target element isolation, and sample dilution) were performed in a class-10 clean lab. Teflon Savillex ${ }^{\circledR}$ beakers were used throughout the study for sample handling and storage. These beakers were previously cleaned with $\mathrm{HNO}_{3}$ and $\mathrm{HCl}$ of pro-analysis purity level (Chem-Lab, Belgium) and further rinsed with ultrapure water (resistivity $\geq 18.2 \mathrm{M} \Omega \mathrm{cm}$ ) obtained from a Milli-Q Element water purification system (Millipore, France).

For sample preparation, pro-analysis-grade acids (ChemLab, Belgium) were further purified by sub-boiling distillation in either quartz $(12 \mathrm{M} \mathrm{HCl})$ or PTFE $\left(14 \mathrm{M} \mathrm{HNO}_{3}\right)$ stills. Ultrapure $9.8 \mathrm{M} \mathrm{H}_{2} \mathrm{O}_{2}$ was purchased from SigmaAldrich (Belgium). Multi-element and single-element standard solutions used for quantitative analysis were prepared from commercially available $1-\mathrm{gL}^{-1}$ stock solutions (Inorganic Ventures, The Netherlands) after proper dilution with $0.4 \mathrm{M} \mathrm{HNO}_{3}$.

All isotope ratios determined are expressed as delta values, i.e., as a relative difference (in per mil) versus a material the isotopic composition of which is used as a reference. For $\mathrm{Cu}$ analysis, an in-house isotopic standard was prepared from a commercially available $1-\mathrm{gL}^{-1}$ stock solution (Inorganic Ventures, The Netherlands, lot $\mathrm{C} 2-\mathrm{Cu} 02116$ ). This inhouse standard was used on a daily basis to reduce the consumption of the valuable NIST SRM 976 isotopic reference material, which is no longer available from NIST. The isotopic composition of the in-house standard was determined relative to the NIST SRM, and it was found to have a $\delta^{65} \mathrm{Cu}$ value of $0.23 \pm 0.03 \%$ \% $(n=68)$. All $\mathrm{Cu}$ delta values included in this paper are expressed relative to the internationally accepted NIST SRM 976 isotopic reference material, so that inter-comparability with other works is directly possible. For Sn analysis, as there is no isotopic reference material available, an in-house isotopic standard was prepared from a commercially available $1-\mathrm{gL}^{-1}$ stock solution (Fluka, Switzerland, lot 1342599), and all Sn delta values are expressed relative to this solution. Unfortunately, unless a certified isotopic standard becomes available for Sn, intercomparability of tin isotope data is not yet possible. Commercially available $1-\mathrm{gL}^{-1}$ stock solutions were also used for the internal standards used for mass bias correction: $\mathrm{Zn}$ (Inorganic Ventures, The Netherlands, lot D2-Zn02061), Ni (SCP Science, Canada, lot SC 3258038), and Sb (SCP Science, Canada, lot SC 7053507).
A bronze-certified reference material (IARM 91D, Analytical Reference Material International, Colorado, USA) was used throughout the study for optimization and validation purposes. This material has a certified major element composition of $82.0 \mathrm{wt} \% \mathrm{Cu}, 7.8 \mathrm{wt} \% \mathrm{~Pb}, 6.5 \mathrm{wt} \% \mathrm{Sn}$, $3.20 \mathrm{wt} \% \mathrm{Zn}$, and $0.4 \mathrm{wt} \% \mathrm{Ni}$.

Polypropylene columns used for $\mathrm{Cu}$ and $\mathrm{Sn}$ isolation were purchased from Bio-Rad (Belgium). These columns have an internal diameter of $8 \mathrm{~mm}$ and are $10 \mathrm{~cm}$ long. Anion exchange resin AG-MP-1 (100-200 mesh) was also purchased from Bio-Rad (Belgium) and used for $\mathrm{Cu}$ isolation. For the selective separation of Sn, the anion-exchange TRU-Spec resin from EICHROM (France) was used and loaded into Bio-Rad polypropylene columns. Ethanol, used for sample cleaning after mechanical cleaning, was purchased from Sigma Aldrich (Belgium).

\section{Samples}

Thirty-two archaeological bronzes originating from the main pre-Roman and Roman archaeological sites in Teruel and Huesca, both located in Aragón (northern Spain), were used to explore the potential of $\mathrm{Cu}$ and $\mathrm{Sn}$ isotopic analysis for archaeological purposes. Samples from Teruel originated from five different sites: Alto Chacón, La Romana, El Palomar, La Loma del Regadio, and La Caridad, while samples from Huesca originated from six different sites: El Campaz, Sancho Abarca, Plaza Lizana, La Codera, Círculo Católico, and Escolapios. All samples are small fragments of household and agricultural objects that have been examined and dated by archaeologists and cover the period from VIIBC to VAD. After digestion (see section "Sample preparation for isotopic analysis" for details), the samples were analyzed by means of quadrupole-based inductively coupled plasma-mass spectrometry (ICP-MS) to determine the major elemental components (see section "Instrumentation and measurements" for details), which were found to be $\mathrm{Cu}(57 \pm 12 \%$; average \pm s) and Sn $(6.9 \pm 2.5 \%)$. These results, together with the fact that oxygen was detected in the samples via scanning electron microscopy combined with energy dispersive X-ray analysis (using a JEOL JSM-6360LV instrument, Japan), indicate alteration of its composition during burial (i.e., oxidation) as otherwise higher values would be obtained. Very low amounts of other common elements found in ancient $\mathrm{Cu}$ alloys, such as $\mathrm{Pb}$ or $\mathrm{Zn}$, were also found in most of the samples.

Sample preparation for isotopic analysis

Before digestion, the samples were polished with a diamond Dremel $^{\circledR}$ tool. Afterward, any corrosion layer or organic residues were removed with diluted $\mathrm{HNO}_{3}$. After this first mechanical and chemical cleaning, the samples were placed in deionized water in an ultrasonic bath for $10 \mathrm{~min}$; subsequently 
they were manually dried with a tissue and further cleaned with ethanol and dried in an oven at $45^{\circ} \mathrm{C}$. Then, 100-mg aliquots of each sample were obtained with a diamond drill and accurately weighed. The material thus obtained was dissolved in $5 \mathrm{~mL}$ of a 1:3 mixture of $14 \mathrm{M} \mathrm{HNO}_{3}$ and $12 \mathrm{M} \mathrm{HCl}$ (aqua regia) in closed screw-top Savillex ${ }^{\circledR}$ Teflon beakers, which were heated on a hot plate at $90-100{ }^{\circ} \mathrm{C}$ for $2 \mathrm{~h}$. For some of the samples, a white precipitate, probably Sn oxides, appeared upon digestion. This precipitate was effectively decomposed by drying down the samples, adding $5 \mathrm{~mL}$ of $12 \mathrm{M} \mathrm{HCl}$, and heating in a closed beaker at $100{ }^{\circ} \mathrm{C}$ for $5 \mathrm{~h}$. The digests obtained were diluted with Milli-Q water to a final volume of $30 \mathrm{~mL}$ and were kept in closed vials until further analysis. For validation of the protocol, the reference material IARM 91D was subjected to the same digestion protocol, and the contents of the major and minor elements were determined with a quadrupole-based ICP-MS instrument (see section "Instrumentation and measurements" for details). Results obtained upon analysis were in good agreement with the certified values in all cases (see Table 1).

$\mathrm{Sn}$ isotopic analysis of the digested bronzes was performed on purified fractions obtained after column exchange chromatography. For this purpose, Bio-Rad polypropylene columns were cleaned with $2 \mathrm{M} \mathrm{HCl}$ and filled with $0.3 \mathrm{~mL}$ of TRUSpec resin [7, 32]. Before use, the resin was rinsed abundantly with Milli-Q water and was allowed to settle. The supernatant was thrown away to eliminate the finest resin particles. Prior to each elution, the resin was pre-cleaned three times by alternately passing fractions of $5 \mathrm{~mL}$ of $0.4 \mathrm{M} \mathrm{HNO}_{3}$ and $5 \mathrm{~mL}$ of Milli-Q water. Afterward, the column was conditioned with $5 \mathrm{~mL}$ of $1 \mathrm{M} \mathrm{HCl}$. For sample loading, $2 \mathrm{~mL}$ of the bronze digests were vaporized to dryness at $70{ }^{\circ} \mathrm{C}$ and retaken in solution with $2 \mathrm{~mL}$ of $1 \mathrm{M} \mathrm{HCl}$. The matrix was quantitatively eluted with $10 \mathrm{~mL}$ of $1 \mathrm{M} \mathrm{HCl}$, while a purified $\mathrm{Sn}$ fraction was obtained with $20 \mathrm{~mL}$ of $1 \mathrm{M} \mathrm{HNO}_{3}$. Immediately after column separation, $10 \mu \mathrm{L}$ of concentrated HF were added to the Sn fraction in order to prevent precipitation. Before isotopic analysis, these fractions were diluted to a final concentration of $1 \mathrm{mgL}^{-1}$ of $\mathrm{Sn}$ with an appropriate volume of $0.4 \mathrm{M} \mathrm{HNO}_{3}$ and were doped with $1 \mathrm{mgL}^{-1}$ of Sb for mass

Table 1 Elemental concentrations for the bronze reference material IARM 91D as determined using quadrupole-based ICP-MS after sample digestion

\begin{tabular}{llllll}
\hline & $\mathrm{Cu}$ & $\mathrm{Zn}$ & $\mathrm{Sn}$ & $\mathrm{Pb}$ & $\mathrm{Ni}$ \\
\hline $\begin{array}{c}\text { PN-ICP-MS } \\
(w / w \%)\end{array}$ & 82.6 & 3.3 & 6.7 & 8.0 & 0.4 \\
$\begin{array}{c}\text { IARM 91 D } \\
\text { certificate } \\
(w / w \%)\end{array}$ & $82.0 \pm 0.4$ & $3.20 \pm 0.04$ & $6.5 \pm 0.1$ & $7.8 \pm 0.1$ & $0.43 \pm 0.01$ \\
\hline
\end{tabular}

The relative uncertainty on the results reported amounts to typically $3-$ $4 \%$ bias correction (see section "Optimization of the MC-ICP-MS measurement protocol: mass bias correction" for details).

$\mathrm{Cu}$ isotopic analysis, on the other hand, was directly performed on the matrix fraction obtained from the $\mathrm{Sn}$ separation protocol described above. Adequate amounts of these matrix fractions were dried at $70{ }^{\circ} \mathrm{C}$, retaken in solution using $1 \mathrm{M} \mathrm{HNO}_{3}$, diluted to a concentration of $500 \mu \mathrm{g}$ $\mathrm{L}^{-1} \mathrm{Cu}$ with $0.4 \mathrm{M} \mathrm{HNO}_{3}$, and doped with $500 \mu \mathrm{gL}^{-1} \mathrm{Ni}$ for mass bias correction.

The possibility of performing $\mathrm{Cu}$ isotopic analysis on purified $\mathrm{Cu}$ solutions was also investigated, and an adaptation of the methodology proposed by Maréchal et al. [33] was used for $\mathrm{Cu}$ isolation. Bio-Rad polypropylene columns (i.d. $8 \mathrm{~mm}$ ) were cleaned with $2 \mathrm{M} \mathrm{HCl}$ and filled with $2 \mathrm{~mL}$ of AG-MP1 (100-200 mesh) strong anion exchange resin. A piece of cotton was used as a stopper on top of the resin bed for reducing possible tailing effects in the $\mathrm{Cu}$ elution [34]. Before use, the AG-MP-1 resin was allowed to settle three to four times in water, and the supernatant was thrown away in order to eliminate the finest resin particles. Prior to each elution, the resin was gently washed with approximately $10 \mathrm{~mL}$ of Milli-Q water and then pre-cleaned three times with $5 \mathrm{~mL}$ of $2 \mathrm{M} \mathrm{HNO}_{3}$ and $4 \mathrm{~mL}$ of Milli-Q water. The resin was subsequently conditioned with $5 \mathrm{~mL}$ of $\left(7 \mathrm{M} \mathrm{HCl}+0.002 \% \mathrm{H}_{2} \mathrm{O}_{2}\right)$. After sample loading ( $1 \mathrm{~mL}$ of sample, corresponding to $20-50 \mu \mathrm{g}$ of $\mathrm{Cu}$ ), the sample matrix was eluted with $10 \mathrm{~mL}$ of $(7 \mathrm{M} \mathrm{HCl}+$ $0.002 \% \mathrm{H}_{2} \mathrm{O}_{2}$ ), and subsequently, $\mathrm{Cu}$ was eluted with $25 \mathrm{~mL}$ of the same solution. Finally, the samples were dried at $70{ }^{\circ} \mathrm{C}$ and retaken into solution with $2 \mathrm{~mL}$ of $1 \mathrm{M} \mathrm{HNO}_{3}$. Prior to isotopic analysis, the samples were diluted to $500 \mu \mathrm{gL}^{-1}$ of $\mathrm{Cu}$ in an appropriate volume of $0.4 \mathrm{M} \mathrm{HNO}_{3}$, and the solution was doped with the proper amount of internal standard for mass bias correction (see section "Optimization of the MC-ICP-MS measurement protocol: mass bias correction" for details).

Instrumentation and measurements

Target element $(\mathrm{Cu}$ and $\mathrm{Sn})$ concentrations in the sample and IARM 91D digests, and the concentrations of the elements tested as internal standards ( $\mathrm{Ni}, \mathrm{Zn}$ and $\mathrm{Sb}$ ), some typical major and minor elements constituting $\mathrm{Cu}$ alloys, and potential interfering elements $(\mathrm{Na}, \mathrm{Mg}, \mathrm{Cd}, \mathrm{Tl}, \mathrm{In}, \mathrm{Fe})$ were determined using a quadrupole-based ICP-MS instrument (Thermo X-Series II, Bremen, Germany), equipped with a $1 \mathrm{mLmin}^{-1}$ quartz concentric nebulizer mounted onto a Peltier-cooled, low-volume conical spray chamber. External calibration versus aqueous standard solutions was relied on, while $100 \mu \mathrm{gL}^{-1}$ of $\mathrm{Ga}$ and $\mathrm{Y}$ acted as internal standards, correcting for potential matrix effects and instrument instability. Instrumental settings and data acquisition parameters for this analysis are summarized in Table 2.

For the isotope ratio measurements, a Neptune MC-ICP-MS instrument (Thermo Scientific, Bremen, Germany) was used. 
Table 2 Instrument settings and data acquisition parameters for the Thermo Scientific X Series II quadrupole-based ICP-MS instrument and for the Thermo Scientific Neptune multi-collector ICP-MS instrument

\begin{tabular}{|c|c|c|c|c|c|c|c|c|}
\hline \multicolumn{3}{|l|}{ Instrument settings } & \multicolumn{6}{|c|}{ Data acquisition parameters } \\
\hline \multicolumn{9}{|c|}{ Thermo Scientific X Series II } \\
\hline RF Power & \multicolumn{2}{|c|}{$1400 \mathrm{~W}$} & \multicolumn{2}{|c|}{ Detector mode } & \multicolumn{4}{|l|}{ Dual } \\
\hline Nebulizer gas flow rate & \multicolumn{2}{|c|}{$0.84-0.90 \mathrm{Lmin}^{-1}$} & \multicolumn{2}{|c|}{ Scanning mode } & \multicolumn{4}{|c|}{ Peak jump } \\
\hline Plasma gas flow rate & \multicolumn{2}{|c|}{$13 \mathrm{Lmin}^{-1}$} & \multicolumn{2}{|c|}{ Dwell time } & \multicolumn{4}{|c|}{$30 \mathrm{~ms}$} \\
\hline Auxiliary gas flow rate & \multicolumn{2}{|c|}{$0.70 \mathrm{Lmin}^{-1}$} & \multicolumn{2}{|c|}{ Sweeps/reading } & \multicolumn{4}{|l|}{106} \\
\hline Sample uptake rate & \multicolumn{2}{|c|}{$1 \mathrm{mLmin}^{-1}$} & \multicolumn{2}{|c|}{ Replicate time } & \multicolumn{4}{|l|}{$55 \mathrm{~s}$} \\
\hline Sampler cone & \multicolumn{2}{|c|}{$\mathrm{Ni}$} & \multicolumn{2}{|c|}{ Number of replicates } & \multicolumn{4}{|l|}{5} \\
\hline Skimmer cone & \multicolumn{2}{|c|}{ Xt type, Ni } & \multicolumn{2}{|c|}{ Nuclides monitored } & \multicolumn{4}{|c|}{$\begin{array}{c}{ }^{54} \mathrm{Fe},{ }^{57} \mathrm{Fe},{ }^{58} \mathrm{Ni},{ }^{62} \mathrm{Ni},{ }^{63} \mathrm{Cu},{ }^{65} \mathrm{Cu},{ }^{64} \mathrm{Zn},{ }^{66} \mathrm{Zn}, \\
{ }^{67} \mathrm{Zn},{ }^{118} \mathrm{Sn},{ }^{120} \mathrm{Sn},{ }^{123} \mathrm{Sb},{ }^{124} \mathrm{Sb},{ }^{206} \mathrm{~Pb},{ }^{207} \mathrm{~Pb}\end{array}$} \\
\hline \multicolumn{9}{|c|}{ Thermo Scientific Neptune MC-ICP-MS } \\
\hline RF power ${ }^{\mathrm{a}}$ & \multicolumn{2}{|c|}{$1150-1250 \mathrm{~W}$} & Integr & & $4.2 \mathrm{~s}$ & and $\mathrm{Sn}$ & & \\
\hline Plasma gas flow rate & $15 \mathrm{Ln}$ & & Numb & & 10 pe & & & \\
\hline Auxiliary gas flow rate & $0.7 \mathrm{~L}$ & & Numb & & 5 for & for $\mathrm{Sn}$ & & \\
\hline Nebulizer gas flow rate ${ }^{a}$ & 0.950 & $\min ^{-1}$ & Measu & ne per sample & $\sim 5-6$ & & & \\
\hline Sampler/skimmer cones & $\mathrm{Ni}$ & & Rinsin & & $3 \mathrm{~min}$ & & & \\
\hline Sample uptake rate & $100 \mu$ & & Mass & & Low 1 & esolving & & \\
\hline Lens settings & $\begin{array}{r}\text { Optim } \\
\text { anal }\end{array}$ & $\begin{array}{l}\text { maximum } \\
\text { al intensity }\end{array}$ & Baseli & ion & $\begin{array}{r}30 \mathrm{cy} \\
\text { mea }\end{array}$ & $\begin{array}{l}.05 \mathrm{~s} \text { ea } \\
\text { ent }\end{array}$ & the star & yery \\
\hline Collector configuration & & & & & & & & \\
\hline Position & L3 & $\mathrm{L} 2$ & $\mathrm{~L} 1$ & $\mathrm{C}$ & H1 & $\mathrm{H} 2$ & $\mathrm{H} 3$ & $\mathrm{H} 4$ \\
\hline Mass for $\mathrm{Cu}$ & ${ }^{60} \mathrm{Ni}$ & - & ${ }^{61} \mathrm{Ni}$ & ${ }^{62} \mathrm{Ni}$ & ${ }^{63} \mathrm{Cu}$ & - & ${ }^{65} \mathrm{Cu}$ & - \\
\hline & ${ }^{63} \mathrm{Cu}$ & ${ }^{64} \mathrm{Zn}$ & ${ }^{66} \mathrm{Zn}$ & ${ }^{67} \mathrm{Zn}$ & ${ }^{68} \mathrm{Zn}$ & - & - & - \\
\hline Mass for $\mathrm{Sn}$ & ${ }^{116} \mathrm{Sn}$ & - & ${ }^{118} \mathrm{Sn}$ & ${ }^{120} \mathrm{Sn}$ & ${ }^{121} \mathrm{Sb}$ & ${ }^{122} \mathrm{Sn}$ & ${ }^{123} \mathrm{Sb}$ & ${ }^{124} \mathrm{Sn}$ \\
\hline
\end{tabular}

${ }^{\text {a }}$ Optimized daily for maximum ${ }^{63} \mathrm{Cu}^{+}$or ${ }^{120} \mathrm{Sn}^{+}$signal intensity

The sample introduction system used consists of a $100 \mu \mathrm{L}$ $\min ^{-1}$ PFA nebulizer mounted onto a high-stability spray chamber [35], a combination of a Scott-type and a cyclonic spray chamber. The instrument settings and data acquisition parameters for $\mathrm{Cu}$ and $\mathrm{Sn}$ isotopic analysis are also included in Table 2.

For $\mathrm{Cu}$ analysis, the only two stable isotopes of this element were monitored, and two different cup configurations were used, depending on whether $\mathrm{Ni}$ or $\mathrm{Zn}$ was used as internal standard for mass bias correction. In the case of $\mathrm{Sn}$, only the even isotopes were measured $\left({ }^{116} \mathrm{Sn},{ }^{118} \mathrm{Sn},{ }^{118} \mathrm{Sn}\right.$, ${ }^{120} \mathrm{Sn},{ }^{122} \mathrm{Sn},{ }^{124} \mathrm{Sn}$ ) to avoid the influence of massindependent fractionation [36], which has been shown to potentially affect the odd-numbered isotopes of Sn [37]. All measurements were conducted at low mass resolving power. In the case of $\mathrm{Cu}$, the possible occurrence of spectral interferences was checked for the sample solutions via mass scan at medium mass resolving power, and no interfering species were detected, for the purified or for the non-purified samples.

Measurements of blanks for both standards (acid blanks) and samples (procedural blanks) were performed at the beginning of every working session so that signal intensities for standards and samples were corrected for the respective blank contributions. Samples and isotopic standards for delta calculation were diluted to a concentration of $1 \mathrm{mg}$ $\mathrm{L}^{-1}$ of $\mathrm{Sn}$ and $\mathrm{Sb}$ and $500 \mu \mathrm{gL}^{-1}$ of $\mathrm{Cu}$ and $\mathrm{Ni}$ or $\mathrm{Zn}$ to avoid variations in concentration from affecting the extent of mass bias. The measurements were carried out in a standard-sample-sample-standard bracketing sequence. The sample introduction system was rinsed with $0.4 \mathrm{M}$ $\mathrm{HNO}_{3}$ after every sample or standard measurement. The signals at $\mathrm{m} / \mathrm{z}$ of 63 and 65 returned to the original blank level after about $1 \mathrm{~min}$ while, at the $\mathrm{m} / \mathrm{z}$ corresponding to the $\mathrm{Sn}$ isotopes, it took about $3 \mathrm{~min}$ to return to the original blank level. To be on the safe side, a rinsing time of $4 \mathrm{~min}$ was used in all cases, ensuring the absence of significant memory effects in all measurements.

The data obtained were treated off-line for mass bias correction and delta calculation after automatic removal of the outliers based on a 2 s-test. To correct for instrumental mass bias, the so-called "revised Russell's law," described by Baxter et al. [38], was used in all cases. This method is based on the application of Eq. 1:

$$
\operatorname{Rcorr}_{\mathrm{X}, \text { sample }}=\operatorname{Rexp}_{\mathrm{X}, \text { sample }} \cdot \frac{\text { Rtheo }_{\mathrm{X}}}{\mathrm{e}^{\mathrm{a}} \cdot\left(\text { Rexp }_{\mathrm{IS}, \text { sample }}\right)^{\mathrm{b}}}
$$


Where $R$ corr $_{X, \text { sample }}$ represents the corrected isotope ratio for the target analyte $(\mathrm{Cu}$ or $\mathrm{Sn})$ in the sample $\left(X=M_{2} / M_{1}\right.$, where $M_{1}$ and $M_{2}$ are the masses of the lighter and heavier isotope, respectively). $R \exp _{X \text {,sample }}$ represents the measured isotope ratio for the target analyte in the sample; $R \exp _{\mathrm{IS} \text {,sample }}$ represents the measured isotope ratio for the internal standard admixed to the sample (i.e., $\mathrm{Ni}$ for $\mathrm{Cu}$ and $\mathrm{Sb}$ for $\mathrm{Sn}$ ), and $R$ theo ${ }_{x}$ corresponds to the theoretical isotope ratio for the target element calculated based on the isotopic abundances given by the IUPAC [39]. On the other hand, a and b correspond to the intercept and the slope of the linear fit obtained when plotting the natural logarithm of the isotope ratio of the IS versus the natural logarithm of the isotope ratio of the target element, measured simultaneously in standard solutions. These standard solutions, in our particular case, were the inhouse standards described in section "Standards and reagents" (either for $\mathrm{Cu}$ or for $\mathrm{Sn}$ ), measured in a standard-standardsample-sample-standard-standard bracketing approach.

Variations in the isotopic composition of $\mathrm{Cu}$ or $\mathrm{Sn}$ were expressed in $\delta \%$ units calculated following Eq. 2:

$\delta=\frac{R_{X, \text { sample }}-R_{X, \text { standard }}}{R_{X, \text { standard }}} \times 1000$

Where $R_{X \text {,sample }}$ is the corrected isotope ratio for the target element obtained for a particular sample by using Eq. 1, and $R_{X \text {,standard }}$ is the average of the corrected ratios for the target element obtained for the in-house isotopic standards measured immediately before and after the sample considered $(n=4)$. All $\mathrm{Cu}$ delta values thus obtained were finally recalculated relative to the internationally accepted NIST SRM 976 isotopic reference material (previously characterized), so that intercomparability with other works is directly possible.

\section{Results and discussion}

Optimization of the MC-ICP-MS measurement protocol: mass bias correction

To achieve accurate isotope ratio data when working with MCICP-MS, it is essential to correct for instrumental mass bias or, in other words, to calibrate the measurement of isotope ratios in the mass spectrometer. The method used for its correction is a critical parameter that needs to be carefully optimized as, in fact, it typically remains the single largest source of uncertainty in the measurement [38]. In the last years, different methods have been applied for this purpose. A summary of the most commonly used, with their pros and cons, and a critical evaluation of these methods can be found in a review by Yang [40] and a book chapter by Meija et al.[41], respectively. In summary, these methods can be formally classified according to two parameters: whether data from the measurand and calibrant are acquired simultaneously and whether the measurand and calibrant are isotope ratios of the same element. Best results can be expected if measurand and calibrant are measured simultaneously (as matrix matching and stability of the instrument are less determining) and, at least in theory, if a different isotope ratio for the same element is used for calibrating the target isotope ratio (as exactly the same behavior in the instrument can be expected for calibrant and measurand). According to this, a very powerful approach for correcting mass bias is based on admixing known amounts of the analyte of interest that are enriched in two isotopes different from the target isotopes, with an isotopic composition perfectly known in advance [42]. The relative amounts of the target and calibrant isotopes are measured simultaneously in the samples, and by applying an appropriate mass bias model for MC-ICP-MS (e.g., exponential law), accurate isotope ratios can be obtained.

One of the main problems of applying this so-called "Double-Spike calibration," besides the need for a highpurity enriched double spike for which the isotopic composition is known, is that at least four isotopes of an element have to be measured, which precludes its use for elements such as $\mathrm{Cu}$. Besides, uncertainty budgets for this method strongly depend on the composition and the amount of the admixed isotopic spikes, and finding the optimal isotopic composition is sometimes a challenge, although mathematical models exist for simplifying the problem [42]. An alternative to this method also frequently used consists of the substitution of the double spike with another element (an internal standard) for which an isotope ratio is known and is used to obtain mass bias corrected ratios for the measurand after applying an appropriate mass bias model. The problem with this easier-to-implement calibration method is that matrix-induced mass bias cannot be fully compensated for and that a perfect matrix separation and close matching of analyte and calibrant concentrations are required for obtaining accurate isotope ratios. In any case, the main challenge for assuring the utility of this method is still the necessity to ensure the accuracy of the mass bias transfer between measurand and calibrant (which is not always the case), as traditional mass bias models rely on the equality between discrimination functions for measurand and calibrant.

This limitation can be obviated by using a regression model for mass bias correction, which takes advantage of the significant temporal drift of the mass bias when using MC-ICP-MS. In our case, the regression method proposed by Baxter et al. [38] was used for obtaining accurate isotopic information, expressed as delta values (see section "Instrumentation and measurements" for a detailed explanation on the application of this method). Although requiring long measurement sessions for controlling the uncertainty associated to the correction process, this method is acknowledged as one of the best choices, as both the matrix-induced mass bias and the temporal mass bias drift can be corrected for [40], and the necessity 
for equal discrimination functions for measurand and calibrant is avoided.

For application of the Baxter correction method, an element with a mass close to that of the target element is selected as internal standard for correcting for mass bias. For $\mathrm{Cu}$ isotopic analysis, two elements are commonly used for this purpose, $\mathrm{Zn}$ [5, 43-48] and Ni [49-54]. According to the literature, both elements seem to be well-suited for mass bias correction affecting the $\mathrm{Cu}$ isotope ratio, although marginal precision improvements have been recorded when $\mathrm{Ni}$ is used [49-54]. As a consequence, a comparative study of $\mathrm{Ni}$ and $\mathrm{Zn}$ performance was carried out in our investigation. For this purpose, all the samples analyzed for their $\mathrm{Cu}$ isotopic composition along the study were separated in two aliquots, each of which was doped with $\mathrm{Zn}$ and $\mathrm{Ni}$, respectively. In the subsequent MC-ICP-MS measurement sessions, either the ${ }^{66} \mathrm{Zn} /{ }^{64} \mathrm{Zn}$ or the ${ }^{62} \mathrm{Ni} /{ }^{60} \mathrm{Ni}$ ratio was relied upon for correcting the measured ${ }^{65} \mathrm{Cu} /{ }^{63} \mathrm{Cu}$ ratios.

Both $\mathrm{Zn}$ and $\mathrm{Ni}$ provided well-defined linear relationships $\left(R^{2}>0.99\right)$ in the $\ln -\ln$ space over a single measurement session (10-12 h) as shown in Fig. 1a, b. The precision obtained when using both internal standards was compared using the NIST 976 isotopic reference material as a quality control sample, which was monitored at the beginning, at the end, and after every four to five samples in every analytical session. In this way, the internal precision for each analytical session and the long-term reproducibility over a year were obtained. Reproducibility values (calculated as $2 \mathrm{~s}$ ) for the $\delta^{65} \mathrm{Cu}$ values obtained for the NIST 976 standard along the period of an entire year $(n=113)$ were $\pm 0.027 \%$ and $\pm 0.039 \%$ for $\mathrm{Ni}$ and $\mathrm{Zn}$, respectively, showing that, as concluded in other recent $\mathrm{Cu}$ isotope ratio studies [49-54], the use of $\mathrm{Ni}$ as internal standard provides superior precision $\left(F\right.$-test; $F_{\text {value }}=2.155 ; F_{\text {critical, }(P=0.05)}=$ 1.366). In any case, both elements are well-suited for mass bias correction of $\mathrm{Cu}$ ratios. For the analysis of ancient bronzes, however, we consider the use of $\mathrm{Ni}$ as more robust than that of $\mathrm{Zn}$, considering that (1) $\mathrm{Ni}$ is less prone to contamination and (2) $\mathrm{Ni}$ is less often present in archaeological bronzes than $\mathrm{Zn}$. Moreover, and although the condition that the mass bias discrimination affecting both the analyte and the internal standard is identical is not necessary when a regression model such as that of Baxter is used for mass bias correction as discussed before [38], the fact that the first ionization potential of $\mathrm{Ni}(7.46 \mathrm{eV})$ is closer to that of $\mathrm{Cu}(7.73 \mathrm{eV})$ than that of $\mathrm{Zn}(9.39 \mathrm{eV})$ is [52] should result in a more similar mass bias effect observed for $\mathrm{Cu}$ and $\mathrm{Ni}$ than for $\mathrm{Cu}$ and $\mathrm{Zn}$. This could in turn explain the slightly better performance observed for the former element. In the following, all $\delta^{65} \mathrm{Cu}$ values reported are based on $\mathrm{Ni}$ mass bias correction, unless otherwise stated.

For $\mathrm{Sn}$ isotopic analysis, on the other hand, the choice of internal standard is limited to $\mathrm{Sb}$, as other elements with masses close to those of $\mathrm{Sn}$ isotopes give rise to isobaric interferences with some of the $\mathrm{Sn}$ isotopes (e.g., ${ }^{112,114,116} \mathrm{Cd}$, $\left.{ }^{115} \mathrm{In},{ }^{120,122,124} \mathrm{Te}\right)[55]$. Also in this case and for all of the ratios monitored during a measurement session lasting 10 $12 \mathrm{~h}$, the correlation recorded in $\ln -\ln$ space was excellent (see Fig. 1c); $R^{2}>0.99$. Reproducibility along a period of 1 month $(n=42)$ for the corrected $\mathrm{Sn}$ isotope ratios monitored (i.e., ${ }^{118} \mathrm{Sn} /{ }^{116} \mathrm{Sn},{ }^{120} \mathrm{Sn} /{ }^{116} \mathrm{Sn},{ }^{122} \mathrm{Sn} /{ }^{116} \mathrm{Sn},{ }^{124} \mathrm{Sn} /{ }^{116} \mathrm{Sn}$, ${ }^{120} \mathrm{Sn} /{ }^{118} \mathrm{Sn},{ }^{122} \mathrm{Sn} /{ }^{118} \mathrm{Sn},{ }^{124} \mathrm{Sn} /{ }^{118} \mathrm{Sn},{ }^{122} \mathrm{Sn} /{ }^{120} \mathrm{Sn}$, ${ }^{124} \mathrm{Sn} /{ }^{120} \mathrm{Sn},{ }^{124} \mathrm{Sn} /{ }^{122} \mathrm{Sn}$ ) in the in-house standard was in the range of $0.003-0.008 \% \mathrm{RSD}$, corresponding to a reproducibility in the delta scale of $0.06 \%$ to $0.16 \%$ o $\mathrm{s}$ for all the ratios monitored.

\section{Isolation of the target elements}

When measuring isotope ratios with MC-ICP-MS, it is generally accepted that the target element needs to be isolated in order to minimize spectral and non-spectral effects originating from the sample matrix [56]. Chemical isolation is usually carried out via ion exchange chromatography. Although many different commercial resins exist, achieving efficient separation with quantitative recovery is not always straightforward, and additional problems, such as oncolumn isotopic fractionation, can arise if the separation protocol is not carefully optimized.

In the case of $\mathrm{Cu}$ isotopic analysis, the possibility of observing on-column isotopic fractionation has been widely acknowledged [33, 52, 57], and, therefore, optimization of the isolation protocol in terms of quantitative $\mathrm{Cu}$ recovery is crucial. At present, the protocols most commonly used for $\mathrm{Cu}$ purification $[46-48,51,58,59]$ are based on the methodology firstly developed by Maréchal et al., which relies on the use of a strong anion exchange resin (AG-MP-1) [33] for isolation of $\mathrm{Cu}$ as $\mathrm{Cu}(\mathrm{II})$. This chromatographic separation, however, is not perfect and still shows problems related to the poor specificity of the resin for this element: (1) difficulty to obtain quantitative recovery and therefore, the necessity to check for possible on-column fractionation; (2) non-efficient removal of potentially interfering elements (e.g., $\mathrm{Na}$, giving rise to formation of ${ }^{40} \mathrm{Ar}^{23} \mathrm{Na}^{+}$, the signal of which overlaps with that of ${ }^{63} \mathrm{Cu}^{+}$); (3) strong dependence of the elution protocol on the sample characteristics. For these reasons, some authors have avoided the use of $\mathrm{Cu}$ column isolation and have proposed alternative approaches such as hand-picking of $\mathrm{Cu}$-containing fractions in $\mathrm{Cu}$ minerals [28, 59], or even direct $\mathrm{Cu}$ isotopic analysis without target element isolation, which could provide acceptable results in some instances [54, 56].

Direct $\mathrm{Cu}$ isotopic analysis of bronze artifacts without prior $\mathrm{Cu}$ isolation could indeed be an interesting option. In fact, $\mathrm{Cu}$ is the major element in bronze samples (60-90\%), and the contribution of other minor and trace elements could 
Fig. 1 Plot of $\ln$ (isotope ratio, internal standard) versus $\ln$ (isotope ratio, target element) obtained for a standard solution of $500 \mu \mathrm{gL}^{-1} \mathrm{Cu}$ doped with a $500 \mu \mathrm{gL}^{-1} \mathrm{Zn}(n=45)$ and $\mathbf{b}$ $500 \mu \mathrm{gL}^{-1} \mathrm{Ni}(n=45)$; $\mathbf{c} \ln -\ln$ plot for a $1 \mathrm{mgL}^{-1}$ solution $\mathrm{Sn}$ doped with $1 \mathrm{mgmL}^{-1} \mathrm{Sb}$ $(n=41)$
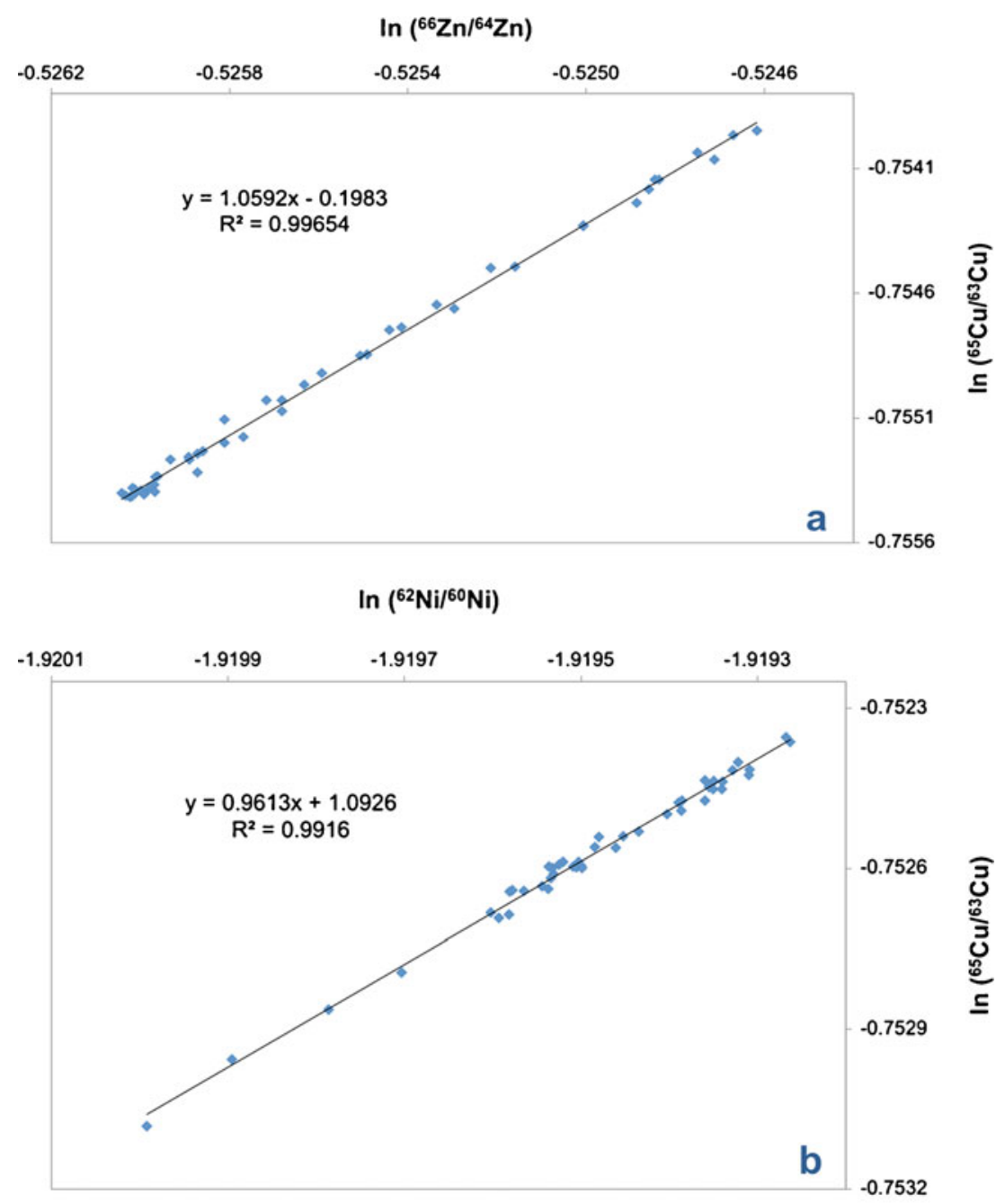

$\ln \left({ }^{123} \mathrm{Sb} /{ }^{121} \mathrm{Sb}\right)$

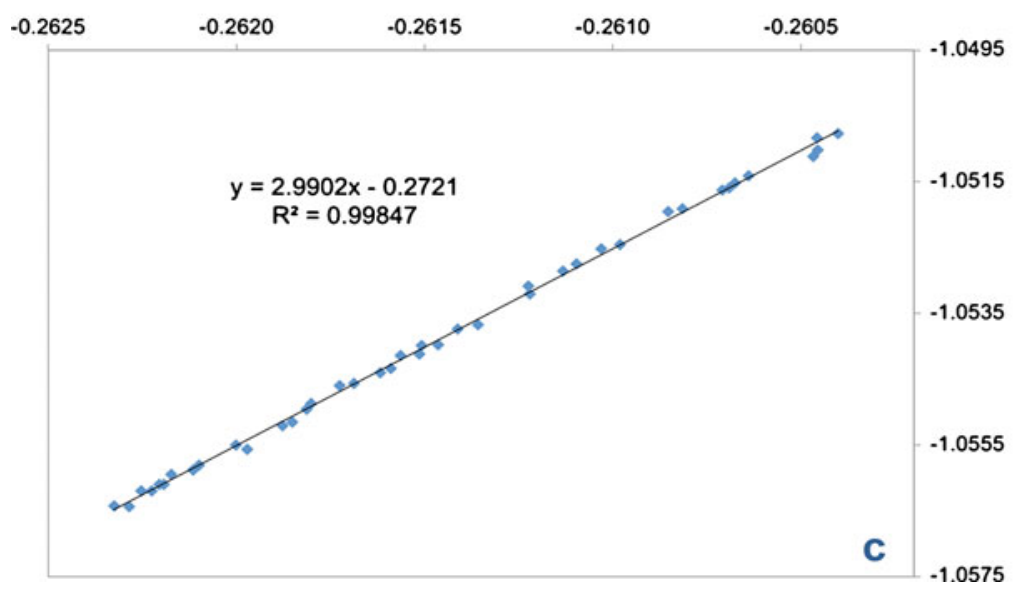

be negligible in terms of potential matrix-related spectral interferences and/or mass bias, especially considering the high dilution factors preceding MC-ICP-MS measurement. To test the validity of this hypothesis and ascertain whether direct $\mathrm{Cu}$ isotopic analysis of ancient bronze samples could be safely performed, several experiments were carried out.
First, the IARM 91D reference material was analyzed for its $\mathrm{Cu}$ isotopic composition: (1) without $\mathrm{Cu}$ isolation and (2) after $\mathrm{Cu}$ isolation with an optimized separation protocol based on the work of Maréchal et al. [33], using AG-MP-1 resin. Although cumbersome and time-consuming, the optimized isolation approach (see section "Sample preparation 
for isotopic analysis" for details) provided good $\mathrm{Cu}$ recovery values for the reference sample $(98 \pm 2 \%$; confidence interval given as analytical uncertainty calculated following the Nordtest calculation approach [60] $k=2, n=5$ ) so that potential on-column isotope fractionation would not have a significant effect on the final result. To further prove this assumption, solutions of NIST SRM $976 \mathrm{Cu}$ where measured before and after column chemistry without detecting any effect of on-column isotope fractionation. Table 3 reports the $\delta^{65} \mathrm{Cu}$ values obtained for analysis of the IARM 91D sample in both cases. As seen from these data, there is no statistically significant difference between the $\delta^{65} \mathrm{Cu}$ values obtained in all instances, suggesting that $\mathrm{Cu}$ isolation is not necessary for bronze samples, at least for those with $\mathrm{Cu}$ contents close to $80 \mathrm{wt} \%$, as in IARM 91D. Moreover, the presence of the elements used as internal standards for mass bias correction in this reference material (3 $\mathrm{wt} \% \mathrm{Zn}$ and $0.4 \mathrm{wt} \% \mathrm{Ni}$ ) did not seem to have a significant influence on the results obtained.

For further assessment of the influence of matrix elements on $\mathrm{Cu}$ isotopic analysis in bronze samples, a pure $\mathrm{Cu}$ solution (the in-house $\mathrm{Cu}$ isotopic standard) doped with different amounts of other elements commonly present in bronzes was relied upon, such that the worst-case scenario, i.e., the lowest ratio of $\mathrm{Cu} /$ matrix elements, could be reproduced. This matrix-matched $\mathrm{Cu}$ solution was prepared taking into account the minimum $\mathrm{Cu}$ content and the maximum concentration levels for other elements present in bronzes according to literature $[4,9,16,27]$ and showed a final composition of $500 \mathrm{mgL}^{-1} \mathrm{Cu}, 120 \mathrm{mgL}^{-1} \mathrm{Sn}, 82 \mathrm{mgL}^{-1}$ $\mathrm{Pb}, 37 \mathrm{mgL}^{-1} \mathrm{Zn}$, and $15 \mathrm{mgL}^{-1} \mathrm{Fe}$. Additionally, $500 \mathrm{mg}$ $\mathrm{L}^{-1} \mathrm{Ni}$ was added as internal standard for mass bias correction. $\delta^{65} \mathrm{Cu}$ values for this solution were also measured without $\mathrm{Cu}$ isolation and after $\mathrm{Cu}$ isolation with the AGMP-1 resin. Results are also included in Table 3. As seen from these data, no statistically significant difference was found between the $\delta^{65} \mathrm{Cu}$ value obtained for the matrixmatched and the pure $\mathrm{Cu}$ solution, respectively. From these

Table 3 Comparison of $\delta^{65} \mathrm{Cu}$ values obtained for the IARM 91D bronze reference material and a synthetic solution (containing some of the major and minor elements accompanying $\mathrm{Cu}$ in bronze samples), without $\mathrm{Cu}$ isolation with $\mathrm{Cu}$ isolation using AG-MP1 and after Sn isolation using TRU-Spec

\begin{tabular}{lrlr}
\hline No separation & $\begin{array}{l}\mathrm{Cu} \text { isolation } \\
\text { AG-MP-1 } \\
\delta^{65} \mathrm{Cu}\end{array}$ & $\begin{array}{l}\text { Cu isolation } \\
\text { TRU-Spec } \\
\delta^{65} \mathrm{Cu}\end{array}$ \\
\hline IARM 91D & $0.143 \pm 0.022$ & $0.144 \pm 0.039$ & $0.144 \pm 0.029$ \\
Synthetic solution & $-0.316 \pm 0.048$ & $-0.313 \pm 0.034$ & $-0.312 \pm 0.045$ \\
\hline
\end{tabular}

All delta values are expressed relative to NIST SRM $976 \mathrm{Cu}$ isotopic reference material. Results are expressed as the average delta value $\pm 2 \mathrm{~s}$ in per mil units $(n=4)$ data, it can be concluded that the presence of the most common matrix elements accompanying $\mathrm{Cu}$ in bronze samples do not influence the $\mathrm{Cu}$ isotope ratio results, even when the $\mathrm{Cu} /$ matrix elements ratio is low and the elements to be used as internal reference for mass bias correction are present to some extent. Therefore, direct $\mathrm{Cu}$ isotopic analysis of digested ancient bronze samples without target element isolation seems feasible in most occasions. For the samples under investigation, analysis with and without $\mathrm{Cu}$ isolation was carried out to further test this hypothesis, and similar results were obtained in all cases. As a consequence, measurement of $\mathrm{Cu}$ isotope ratios in bronze samples without target element isolation is recommended, as it provides much higher sample throughput and avoids the risks of possible on-column fractionation and contamination.

For $\mathrm{Sn}$ isotopic analysis, the situation is not so favorable, as this element only represents up to $15 \%$ (in the best case) of the final bronze formulation, and thus, there is a higher risk of matrix effects if the analyte is not isolated. Moreover and unlike $\mathrm{Cu}$, several of the $\mathrm{Sn}$ isotopes targeted suffer from potential isobaric interference $\left({ }^{112} \mathrm{Cd},{ }^{114} \mathrm{Cd},{ }^{116} \mathrm{Cd}\right.$, $\left.{ }^{115} \mathrm{In},{ }^{120} \mathrm{Te},{ }^{122} \mathrm{Te},{ }^{124} \mathrm{Te}\right)$, and hence, chemical isolation of Sn seems mandatory. For many years, it was assumed that natural isotopic variation for Sn was inexistent or only very small [61-64], and therefore, isolation of this element with the purpose of isotopic analysis has received little attention. The first attempt to separate Sn with ion exchange chromatography was done on meteorite material in the 1960s [61, $62]$. Both anion and cation exchange resins were tested, and the high affinity of Sn for hydrochloric acid was exploited in both instances. Later on, some other chromatographic [65-67], extraction [68], and precipitation [69] protocols were presented for $\mathrm{Sn}$ isolation, although most of these protocols were characterized by long procedures, low Sn recoveries, and/or insufficient separation from potentially interfering elements. In this work, a faster and simpler procedure first suggested by $\mathrm{Yi}$ et al. [66] for $\mathrm{Sn}$ isolation from basalts and recently used by Haustein et al. for the isotopic analysis of $\mathrm{Sn}$ ores and one bronze object [7] was adopted. This protocol relies on the use of a TRU-Spec resin, which selectively and strongly retains $\mathrm{Sn}, \mathrm{U}, \mathrm{Mo}$, and some actinide elements from a diluted $\mathrm{HCl}$ medium, while most of the other metals are not retained on the column [32]. In a second step, $\mathrm{Sn}$ is recovered with diluted $\mathrm{HNO}_{3}$ (see section "Sample preparation for isotopic analysis" for experimental details). For the purpose of fine-tuning the separation protocol for the bronze samples, a synthetic solution containing the common elements accompanying $\mathrm{Sn}$ in bronze formulations, as well as $\mathrm{Cd}$, In, and Te as elements giving rise to isobaric interferences was prepared from monoelement standard solutions $\left(200 \mathrm{mgL}^{-1}\right.$ of $\mathrm{Cu}, 5 \mathrm{mgL}^{-1}$ of $\mathrm{S}$, $20 \mathrm{mgL}^{-1}$ of $\mathrm{Pb}$ and of $\mathrm{Zn}$, and $10 \mathrm{mgL}^{-1}$ of $\mathrm{Cd}$, In, and $\mathrm{Sb}$ ). Figure 2 shows the elution profile for the elements present in 
Fig. 2 Elution profile for a synthetic solution containing $\mathrm{Sn}, \mathrm{Cu}, \mathrm{Zn}, \mathrm{Cd}, \mathrm{In}, \mathrm{Sb}, \mathrm{Te}$, and $\mathrm{Pb}$ from a BioRad polypropylene column packed with $0.3 \mathrm{mg}$ of dry TRU-Spec resin. $f(\mathrm{SL})=2 \mathrm{~mL}$ of $1 \mathrm{M} \mathrm{HCl}$ for sample loading, $f(\mathrm{~m} x)=$ $2 \mathrm{~mL}$ of $1 \mathrm{M} \mathrm{HCl}$ for matrix elution fraction $x, f(\operatorname{Sn} x)=2 \mathrm{~mL}$ of $1 \mathrm{M} \mathrm{HNO}_{3}$ for Sn elution fraction $x$

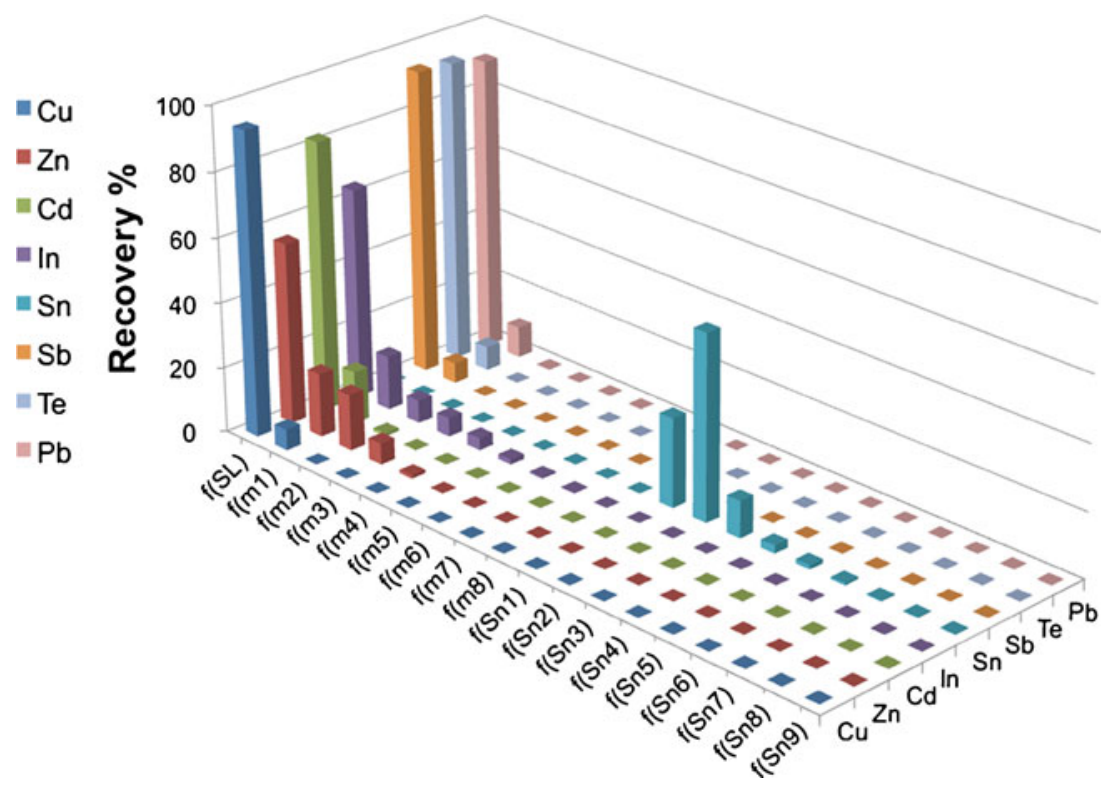

this synthetic solution following the optimized separation protocol with the TRU-Spec resin described in section "Sample preparation for isotopic analysis." As seen from this figure, the matrix elements are easily separated off in a first phase with $12 \mathrm{~mL}$ of $1 \mathrm{M} \mathrm{HCl}$, while $\mathrm{Sn}$ is strongly retained on the column and is only eluted when the column is flushed with $1 \mathrm{M} \mathrm{HNO}_{3}$. This isolation protocol provided good Sn recoveries for the IARM 91D reference material $(98 \pm 2 \%$, confidence interval given as analytical uncertainty calculated by using the Nordtest calculation approach [60] $k=2, n=5$ ) and did not induce isotope fractionation when tested on the inhouse $\mathrm{Sn}$ isotopic standard (measurements before and after column separation).

On the other hand, $\mathrm{Cu}$ is quantitatively recovered in the matrix fraction, which, in principle and considering our previous conclusions about $\mathrm{Cu}$ separation, would allow direct $\mathrm{Cu}$ isotopic analysis in this fraction. In order to test this possibility, the $\mathrm{Cu}$-containing fraction obtained from the TRU-Spec column separation protocol performed on the IARM 91D reference material was analyzed for its $\mathrm{Cu}$ isotope ratio, and the results obtained were compared with those obtained without any column separation and after AG-MP-1 separation. Results of this analysis are also gathered in Table 3. As can be seen from these data, there is no statistically significant difference among the results, further proving that $\mathrm{Sn}$ and $\mathrm{Cu}$ isotopic analysis in bronze samples can be performed with the use of a single separation protocol using TRU-Spec resin. Consequently, this working methodology was applied to the set of archaeological samples under investigation.

Copper and tin isotope ratios of the archaeological bronzes

Finally, the protocol optimized for $\mathrm{Cu}$ and $\mathrm{Sn}$ isotopic analysis of bronze samples was applied to the set of archaeological bronzes under investigation. For the purpose of measurement validation, results for $\mathrm{Sn}$ isotope ratios were plotted in a three-isotope space [1]. Data for the five Sn isotopes measured $\left({ }^{116} \mathrm{Sn},{ }^{118} \mathrm{Sn},{ }^{120} \mathrm{Sn},{ }^{122} \mathrm{Sn}\right.$, and $\left.{ }^{124} \mathrm{Sn}\right)$ are plotted in Fig. 3a, b, wherein the information is given in the delta scale, with respect to the Sn in-house isotopic standard. The lighter isotope measured, ${ }^{116} \mathrm{Sn}$, is used as common reference for delta calculation in both graphs. Results included in these figures serve as a means of quality control for the measurement protocol for $\mathrm{Sn}$, as all $\mathrm{Sn}$ isotope data fall on a straight line in agreement with the theoretical fractionation curve, and there is no evidence of spectral interferences on any of the $\mathrm{Sn}$ isotopes measured for the bronze samples (the line passes close to zero). $\mathrm{As} \mathrm{Cu}$ only has two isotopes, this validation protocol could not be carried out for this element.

Figure 4 summarizes the most significant isotope ratio results for $\mathrm{Sn}$ and $\mathrm{Cu}$ analysis of the bronze samples, combining the average $\delta^{65} \mathrm{Cu}$ (calculated against the NIST 976 $\mathrm{Cu}$ isotopic standard) and the average $\delta^{122} \mathrm{Sn} /{ }^{116} \mathrm{Sn}$ (calculated against the in-house $\mathrm{Sn}$ isotopic standard) obtained for four different determinations. An extensive table containing the isotopic data obtained for the set of samples analyzed in this work is included in the Electronic supplementary material (Table S1 and Table S2).

As seen in Fig. 4, all the bronze objects fit in a large cluster without any evident group classification. Dispersion of the isotopic composition of the different samples is, on the other hand, rather limited, with most of the samples showing a $\delta^{65} \mathrm{Cu}$ between $-0.8 \%$ and $+0.3 \%$, and $\delta^{122} \mathrm{Sn} /{ }^{116} \mathrm{Sn}$ varying from $0.09 \%$ to $0.65 \%$. Incorporation of the $\mathrm{Cu} / \mathrm{Sn}$ relative contents and/or the rest of the $\mathrm{Sn}$ isotope ratios did not improve the situation in terms of sample grouping. 
Fig. 3 Three-isotope plots involving the five $\mathrm{Sn}$ isotopes measured $\left({ }^{116} \mathrm{Sn},{ }^{118} \mathrm{Sn},{ }^{120} \mathrm{Sn}\right.$,

${ }^{122} \mathrm{Sn}$, and ${ }^{124} \mathrm{Sn}$ ) plotted in the delta scale, with respect to the in-house isotopic standard used for the investigation: a

$\delta^{124} \mathrm{Sn} /{ }^{116} \mathrm{Sn}$ versus

$\delta^{120} \mathrm{Sn} /{ }^{116} \mathrm{Sn}$ and $\mathbf{b}$

$\delta^{122} \mathrm{Sn} /{ }^{116} \mathrm{Sn}$ versus

$\delta^{118} \mathrm{Sn} /{ }^{116} \mathrm{Sn}$. Measurements

correspond to four replicates (separate sample preparation) performed during four different sessions. Error bars represent analytical uncertainty $(k=2)$ calculated following the Nordtest calculation approach [60]; non-visible error bars are the size of the data markers on the plot or smaller. The lighter isotope measured, ${ }^{116} \mathrm{Sn}$, is used as common reference for isotope ratio calculation
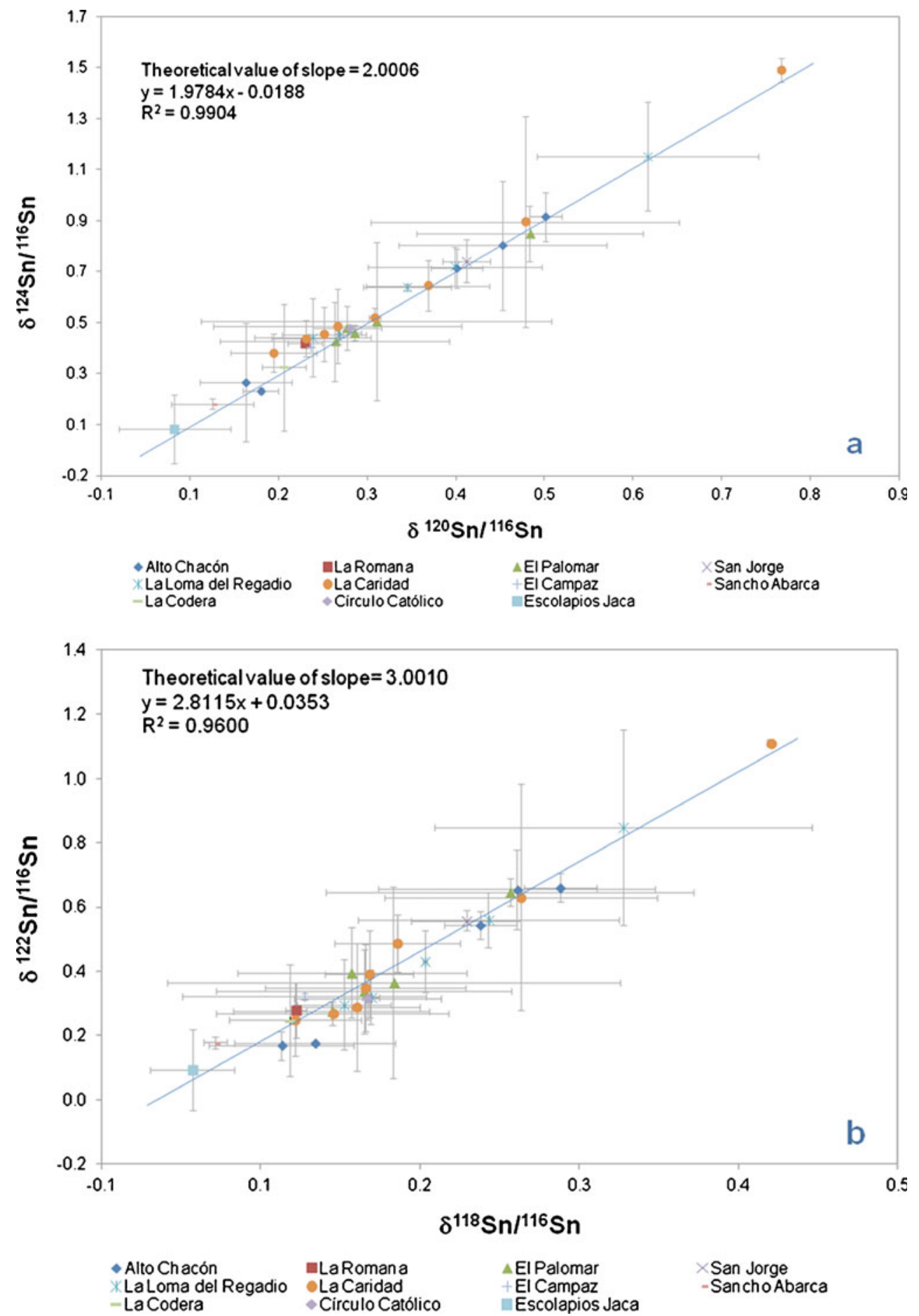

Different tentative interpretations of the results for the samples under investigation are possible. Recycling and remelting of the bronze objects through the years could explain the relatively low isotopic variability among the samples. This hypothesis would be sustained by the fact that all samples come from common household and working objects, for which not the best raw materials would have been used. On the other hand, the fact that the same source of raw materials was used for all the bronze samples investigated cannot be excluded, considering the narrow geographical area covered by the different sites where the samples were found. To ascertain the possible origin for this (hypothetically) single ore source, comparison of isotopic data obtained for $\mathrm{Cu}$ with results published by other scientists is possible as all measurements are traceable to the NIST 976 isotopic reference material. In this regard, the data obtained compare well with the results obtained in the study of Klein $[25,27]$ on Roman coins and copper metal 
Fig. 4 Isotope ratio results for $\mathrm{Sn}$ and $\mathrm{Cu}$ analysis of the bronze samples combining $\delta^{122} \mathrm{Sn} /{ }^{116} \mathrm{Sn}$ (calculated against the in-house $\mathrm{Sn}$ isotopic standard) versus $\delta^{65} \mathrm{Cu}$ (calculated against NIST SRM $976 \mathrm{Cu}$ isotopic standard). Error bars represent analytical uncertainty $(k=2)$ calculated following the Nordtest calculation approach [60] for four different replicates performed during four different sessions; non-visible error bars are the size of the data markers on the plot or smaller

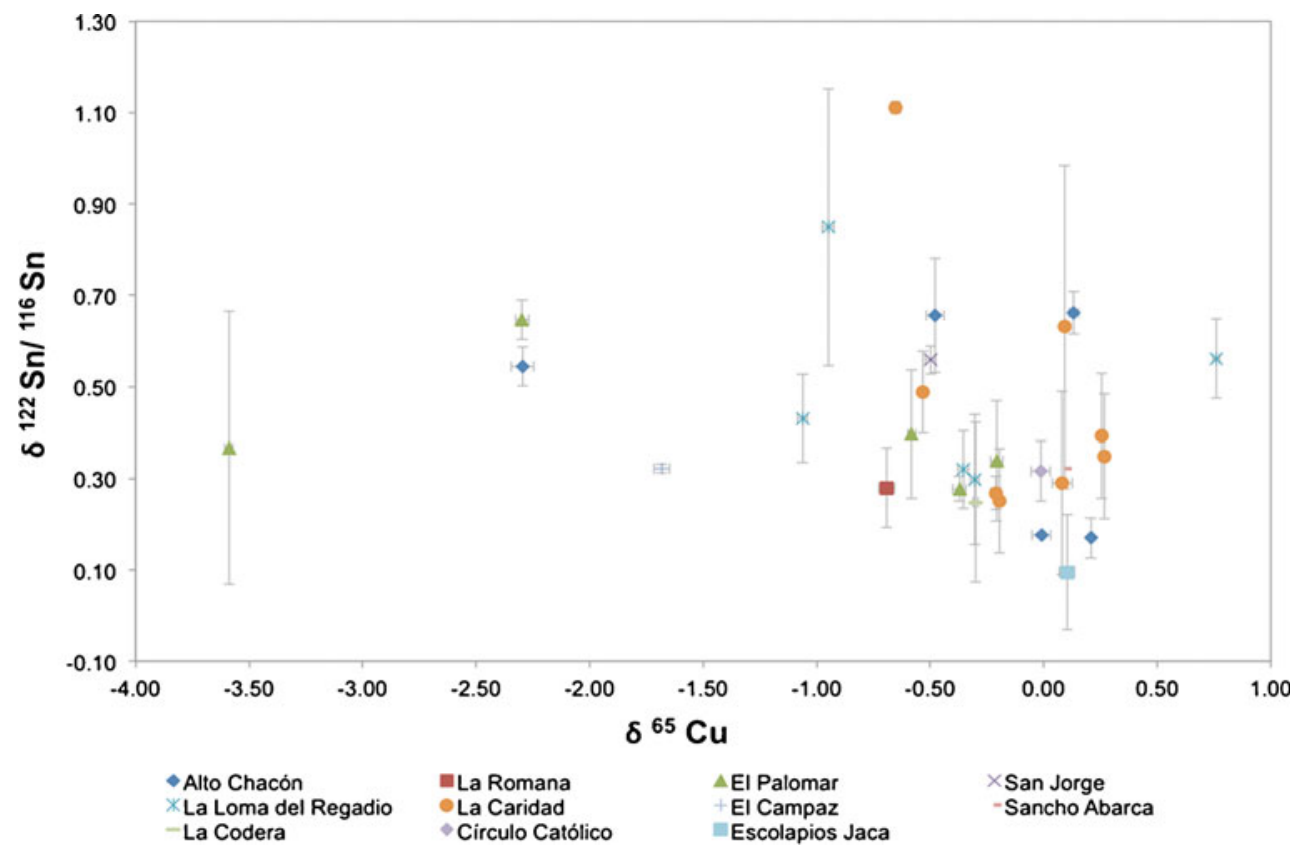

objects from the south of Spain, although this conclusion has to be further tested and validated with analysis of alternative samples.

In the case of Sn, the hypothesis of a single ore source is much more likely, as Sn mine sources were scarce in Europe compared with those of other metals [7]. In fact, the dispersion of the Sn delta values found for these samples is in the same range or even lower than that observed in previous studies for a single Sn ore site [7]. From this point, and in order to further test the feasibility for $\mathrm{Sn}$ ore provenancing by using isotopic information, additional analysis on alternative sets of samples and/or ores from known or expected different origin should be carried out. In the authors' opinion, it is sufficiently proven that the analytical protocol developed provides reliable results, so that this investigation can be carried out.

\section{Conclusions}

The present study represents the first phase of a project investigating the potential of $\mathrm{Cu}$ and $\mathrm{Sn}$ isotopic analysis for the fingerprinting and/or provenancing of archaeological bronzes and deals with optimization of the analytical methodology. In this regard, we have demonstrated that:

1. For $\mathrm{Cu}$ isotopic analysis, mass bias discrimination can be successfully corrected using either $\mathrm{Zn}$ or $\mathrm{Ni}$ as internal standard. Both elements provide reproducibility values ( 1 year period) in the range of $\pm 0.03 \%$ o $(2 \mathrm{~s})$ for a quality control standard. $\mathrm{Ni}$, however, provides superior precision values, and its use seems more robust due a lower risk of contamination, a similar ionization potential to that of $\mathrm{Cu}$ and lower $\mathrm{Ni}$ contents in $\mathrm{Cu}$ alloys.
2. For archaeological bronzes, the $\mathrm{Cu}$ isotope ratio can be directly measured without prior column isolation with a precision equal to that for the corresponding purified solution using AG-MP-1 anion exchange resin (reproducibility in the range of $\pm 0.02 \%$ in the delta scale as $2 \mathrm{~s}, n=5$ ). Minor elements typically present in bronze $\mathrm{Cu}$ alloys (i.e., $\mathrm{Sn}, \mathrm{Zn}, \mathrm{Pb}, \mathrm{Ni}$ ), including those used for mass bias correction, do not affect the results for $\mathrm{Cu}$ isotopic analysis at their usual concentration levels. In this regard, there is no evidence of spectral interference or a matrix-induced effect on the extent of mass bias discrimination with the measurement methodology used.

3. Sn isolation needed for $\mathrm{Sn}$ isotopic analysis can be carried out using the anion-exchange TRU-Spec resin, which provides Sn recovery values close to $100 \%$ and does not introduce on-column isotope fractionation. $\mathrm{Cu}$, on the other hand, can be quantitatively recovered together with the bronze matrix with this isolation protocol. Isotopic analysis of this $\mathrm{Cu}$-containing fraction provides $\delta^{65} \mathrm{Cu}$ results similar to those obtained after AG-MP-1 Cu isolation. $\mathrm{Cu}$ and $\mathrm{Sn}$ isotopic analysis of bronze $\mathrm{Cu}$ alloys can therefore be carried out after a single chromatographic separation using the TRU-Spec resin.

4. Tin isotope ratios can be directly measured in the $\mathrm{Sn}$ isolate as obtained from the TRU-Spec column. The use of $\mathrm{Sb}$ as an internal standard for mass bias correction provides good reproducibility for all isotope ratios monitored (in the range of $0.06-0.16 \% 2 \mathrm{~s}$ ) and excellent validation results using three-isotope plots.

As for the isotopic data interpretation, further work with the optimized methodology needs to be carried out to 
ascertain the usefulness of $\mathrm{Cu}$ and $\mathrm{Sn}$ isotopic analysis for provenancing/discriminating purposes. In this regard, it has been sufficiently proven that the method developed in this work provides reliable results so that further investigation concerning this issue can be carried out. In the case of Sn, however, progress in this direction is hampered by the fact that no reference material or standard is available for this element at present, so that isotopic data from different labs cannot be directly compared.

Acknowledgments R. Alloza and M. P. Marzo are kindly acknowledged for providing access to the samples investigated in this work. M.A. acknowledges the Flemish Research Foundation (FWO) for her postdoctoral grant. F.V. acknowledges the FWO for financial support under the form of a research project (G002111N). M.R. acknowledges the Spanish Ministry of Science and Innovation (Project CTQ200908606). F.V. and M.R. acknowledge the Special Research Foundation (BOF) of Ghent University for financial support of their bilateral cooperation.

\section{References}

1. Vanhaecke F, Degryse P (2012) Isotopic analysis. Fundamentals and applications using ICP-MS. Wiley-VCH, Weinheim

2. Vanhaecke F, Balcaen L, Malinovsky D (2009) Use of singlecollector and multi-collector ICP-mass spectrometry for isotopic analysis. J Anal At Spectrom 24:863-886

3. Balcaen L, Moens L, Vanhaecke F (2010) Determination of isotope ratios of metals (and metalloids) by means of inductively coupled plasma-mass spectrometry for provenancing purposes - a review. Spectrochim Acta B 65:769-786

4. Gale NH, Stos-Gale ZA (1982) Bronze Age copper sources in the Mediterranean - a new approach. Science 216:11-19

5. Zhu XK, O’Nions RK, Guo Y, Belshaw NS, Rickard D (2000) Determination of natural $\mathrm{Cu}$-isotope variation by plasma source mass spectrometry: implications for use as geochemical tracers. Chem Geol 163:139-149

6. Albarède F, Beard B (2004) Analytical method for non-traditional isotopes. In: Johnson CM, Beard BL, Albarède F (eds) Rewies in mineralogy and geochemistry, vol. 55, geochemistry of nontraditional stable isotopes. Mineralogical Society of America, Washington

7. Haustein M, Gillis C, Pernicka E (2010) Tin isotopic analysis-a new method for solving old questions. Archaeometry 52:816-832

8. Gale NH, Woodhead AP, Stos-Gale ZA, Walder A, Bowen A (1999) Natural variations detected in the isotopic composition of copper: possible applications to archaeology and geochemistry. Int J Mass Spectrom 184:1-9

9. Rehener T, Pernicka E (2008) Coins, artefacts and isotopesarchaeometallurgy and archaeometry. Archaeometry 50:232-248

10. Radivojevic M, Rehren T, Pernicka E, Silvar D, Brauns M, Boric D (2010) On the origin of extractive metallurgy: new evidence from Europe. J Archaeol Sci 37:2775-2787

11. Resano M, Marzo MP, Alloza R, Saénz C, Vanhaecke, Yang L, Willie S, Sturgeon RE (2010) Laser ablation single-collector inductively coupled plasma mass spectrometry for lead isotopic analysis to investigate evolution of the Bilbilis mint. Anal Chim Acta 677:55-63

12. Cattin F, Guénette-Beck B, Besse M, Serneels V (2009) Lead isotopes and archaeometallurgy. Archaeol Anthtopol Sci 1: $137-148$
13. Resano M, Marzo P, Pérez-Arantegui J, Aramendía M, Cloquet C, Vanhaecke F (2008) Laser ablation-inductively coupled plasmadynamic reaction cell-mass spectrometry for the determination of lead isotope ratios in ancient glazed ceramics for discriminating purposes. J Anal At Spectrom 23:1182-1191

14. Thibodeau AM, Chesley JT, Ruiz J (2012) Lead isotope analysis as a new method for identifying material culture belonging to the Vázquez de Coronado expedition. J Archaeol Sci 39:58-66

15. Attanasio D, Bultrini G, Ingo GM (2001) The possibility of provenancing a series of bronze Punic coins found at Tharros (Western Sardinia) using the literature lead isotope database. Archaeometry 43:529-547

16. Durali-Müller S (2005) Roman lead and copper mining in Germany - their origin and development through time, deduced from lead and copper isotope provenance studies. http://www. mineralogie.uni-frankfurt.de/petrologie-geochemie/forschung/ dissertationen/diss0106/index.html

17. Marzo P, Laborda F, Pérez-Arantegui J (2007) A simple method for the determination of lead isotope ratios in ancient glazed ceramics using inductively coupled plasma: quadrupole mass spectrometry. At Spectrosc 28:195-201

18. Stos-Gale ZA (1995) Isotope archaeology — a review. In: Beavis J, Barker K (eds) Science and site: evaluation and conservation. Bournemouth University School of Conservation Sciences, Dorset

19. Gale N (2001) Archaeology, science-based archaeology and the Mediterranean Bronze Age metals trade: a contribution to the debate. Eur J Archaeol 4:113-130

20. Wilson L, Pollard AM (2001) The provenance hypothesis. In: Brothwell DR, Pollard AM (eds) Handbook of archaeological sciences. Wiley \& Sons, Chichester

21. De Wannemacker G, Vanhaecke F, Moens L, Van Mele A, Thoen H (2000) Lead isotopic and elemental analysis of copper alloy statuettes by double focusing sector field ICP mass spectrometry. A Anal At Spectrom 15:323-327

22. Begemann F, Schmitt-Strecker, Pernicka E, Lo Schiavo F (2001) Chemical composition and lead isotopy of copper and bronze from Neuragic Sardinia. Eur J Archaeol 4:43-85

23. Desaulty AM, Telouk P, Albalat E, Albarède F (2011) Isotopic Ag$\mathrm{Cu}-\mathrm{Pb}$ record of silver circulation through 16th-18th century Spain. PNAS 108:9002-9900

24. Fortunato G, Ritter A, Fabian D (2005) Old masters' lead white pigments: investigation of paintings from the $16^{\text {th }}$ to the $17^{\text {th }}$ century using high precision lead isotope abundance ratios. Analyst 130:898-906

25. Klein S, Brey GP, Durali-Müller S, Lahaye Y (2010) Characterization of raw metal sources used for the production of copper and copper-based objects with copper isotopes. Archaeol Anthropol Sci 2:45-56

26. Hull S, Fayek M, Mathien FJ, Shelley P, Durand KR (2008) A new approach to determining the geological provenance of turquoise artifacts using hydrogen and copper stable isotopes. J Archaeol Sci 35:1355-1369

27. Klein S, Lahaye Y, Brey GP (2004) The Early Roman Imperial AES coinage II: tracing the copper sources by analysis of lead and copper isotopes-copper coins of Augustus and Tiberius. Archaeometry 46:469-480

28. Mathur R, Titley S, Hart G, Wilson M, Davignon M, Zlatos C (2009) The history of the United States cent revealed through copper isotope fractionation. J Archaeol Sci 36:430-433

29. Begemann F, Kallas K, Schmitt-Strecker S, Pernicka E (1999) In: Hauptmann A, Pernicka E, Rehren T, Yalcin Ü (eds) The beginnings of metallurgy. Der Anschnitt, Beiheft, Deutsches BergbauMuseum, Bochum

30. Klein S, Doumergue C, Lahaye Y, Brey GP, Von Kaenel HM (2009) The lead and copper isotopic composition of copper ores from the Sierra Morena (Spain)-Análisis de los isotopos de 
plomo y de cobre de los minerales de cobre de la Sierra Morena (Spain) por MC-ICP-MS. J Iberian Geol 35:59-68

31. Gale NH (1997) The isotopic composition of tin in some ancient metals and the recycling problem in metal provenancing. Archaeometry 39:71-82

32. Huff EA, Huff DR (1993) TRU-Spec and RE-Spec chromatography: basic studies and applications. in 34th ORNL/DOE Conference on Analytical Chemistry in Energy Technology, Gatlinburg, Tennessee

33. Maréchal CN, Télouk P, Albarède F (1999) Precise analysis of copper and zinc isotopic compositions by plasma-source mass spectrometry. Chem Geol 156:251-273

34. Van Heghe L, Engström E, Rodushkin I, Cloquet C, Vanhaecke F (2012) Isotopic analysis of the metabolically relevant transition metals $\mathrm{Cu}, \mathrm{Fe}$ and $\mathrm{Zn}$ in human blood from vegetarians and omnivores using multi-collector ICP-mass spectrometry. J Anal At Spectrom 27:1327-1334

35. Krachler M, Rausch N, Feuerbacher H, Kelmens P (2005) A new HF-resistant tandem spray chamber for improved determination of trace elements and $\mathrm{Pb}$ isotopes using inductively coupled plasmamass spectrometry. Spectrochim Acta B 60:865-869

36. Epov VN, Malinovskiy D, Vanhaecke F, Bégué D, Donard OFX (2011) Modern mass spectrometry for studying mass-independent fractionation of heavy stable isotopes in environmental and biological sciences. J Anal At Spectrom 26:1142-1152

37. Malinovsky D, Moens L, Vanahaeke F (2009) Isotopic fractionation of Sn during methylation and demethylation reactions in aqueous solution. Environ Sci Technol 43:4399-4404

38. Baxter DC, Rodushkin I, Engström E, Malinovsky D (2006) Revised exponential model form mass bias correction using an internal standard for isotope ratio measurements by multicollector inductively coupled plasma mass spectrometry. J Anal At Spectrom 21:427-430

39. De Laeter JR, Bohlke JK, De Bievre P, Hidaka H, Peiser HS, Rosman KJR, Taylor PDP (2003) Atomic weights of the elements: Review 2000. Pure Appl Chem 75:683-800

40. Yang L (2009) Accurate and precise determination of isotopic ratio by MC-ICP-MS: a review. Mass Spectrom Rev 28:990-1011

41. Meija J, Yang L, Mester Z, Sturgeon R (2012) Correction of instrumental mass discrimination for isotope ratio determination with multi-collector inductively coupled plasma mass spectrometry in isotopic analysis. Fundamentals and applications using ICPMS. Wiley-VCH, Weinheim

42. Moeller K, Schoenberg R, Pedersen RB, Weiss D, Dong S (2012) Calibration of the new certified reference materials ERM-AE633 and ERM-AE647 for copper and IRMM-3702 for zinc isotope amount ratio determinations. Geost Geoanal Res 35:177-199

43. Mason TFD, Weiss DJ, Horstwood M, Parrish RR, Russell SS, Mullane E, Coles BJ (2004) High-precision $\mathrm{Cu}$ and $\mathrm{Zn}$ isotope analysis by plasma source mass spectrometry part 1 . Spectral interferences and their correction. J Anal At Spectrom 19:209-217

44. Mason TFD, Weiss DJ, Horstwood M, Parrish RR, Russell SS, Mullane E, Coles BJ (2004) High-precision $\mathrm{Cu}$ and $\mathrm{Zn}$ isotope analysis by plasma source mass spectrometry part 2 . Correcting for mass discrimination effects. J Anal At Spectrom 19:218-226

45. Archer C, Vance D (2004) Mass discrimination correction in multiple-collector plasma source mass spectrometry: an example using $\mathrm{Cu}$ and $\mathrm{Zn}$ isotopes. J Anal At Spectrom 19:656-665

46. Marthur R, Titley S, Barra F, Brantley S, Wilson M, Phillips A, Munizaga V, Maksaev V, Vervoort J, Hart G (2009) Exploration potential of $\mathrm{Cu}$ isotope fractionation in porphyry copper deposits. $\mathrm{J}$ Geochem Explor 102:1-6

47. Borrok DM, Wanty RB, Ridley WI, Wolf R, Lamothe RJ, Adams M (2007) Separation of copper, iron, and zinc from complex aqueous solutions for isotopic measurement. Chem Geol 242:400-414
48. Chapman B, Mason TFD, Weiss DJ, Coles BJ, Wilkinson JJ (2005) Chemical separation and isotopic variations of $\mathrm{Cu}$ and $\mathrm{Zn}$ from five geological reference materials. Geost Geoanal Res 30:516

49. Markl G, Lahaye Y, Schwinn G (2006) Copper isotopes as monitors of redox processes in hydrothermal mineralization. Geochim Cosmochim Acta 70:4215-4225

50. Li W, Jackson SE, Pearson NJ, Alard O, Chappell BW (2009) The $\mathrm{Cu}$ isotopic signature of granites from the Lachlan Fold Belt, SE Australia. Chem Geol 258:38-49

51. Asael D, Matthews A, Bar-Matthews M, Halicz L (2009) Copper isotope fractionation in sedimentary copper mineralization (Timna Valley, Israel). Chem Geol 262:147-158

52. Larner F, Rehkämper M, Coles BJ, Kreissig K, Weiss DJ, Sampson B, Unsworth C, Strekopytov S (2011) A new separation procedure for $\mathrm{Cu}$ prior to stable isotope analysis by MC-ICP-MS. J Anal At Spectrom 26:1627-1632

53. Ehrlich S, Butler I, Halicz L, Rickard D, Oldroyd A, Matthews A (2004) Experimental study of the copper isotope fractionation between aqueous $\mathrm{Cu}$ (II) and covellite $\mathrm{CuS}$. Chem Geol 209:259-269

54. Ehrlich S, Ben-Dor L, Halicz L (2004) Precise isotope ratio measurement by multi collector-ICP-MS without matrix separation. Can J Anal Sci Spetrosc 49:136-147

55. Clayton RE, Andersson P, Gale NH, Gillis C, Whitehouse M (2002) Precise determination of the isotopic composition of tin using MC-ICP-MS. J Anal At Spectrom 17:1248-1256

56. Ikerata K, Notsu K, Hirata T (2008) In situ determination of $\mathrm{Cu}$ isotope ratios in copper-rich materials by NIR femtosecond LAMC-ICP-MS. J Anal At Spectrom 23:1003-1008

57. Maréchal CN, Albarède F (2002) Ion-exchange fractionation of copper and zinc isotopes. Geochim Cosmochim Acta 66: 1499-1509

58. Haest M, Muchez P, Petit JCJ, Vanhaecke F (2009) Cu isotope ratio variations in the Dikulushi $\mathrm{Cu}-\mathrm{Ag}$ deposit, DRC: of primary origin or induced by supergene reworking? Econ Geol 104: $1055-1064$

59. Larson PB, Maher K, Ramos FC, Chang Z, Gaspar M, Meinert LD (2003) Copper isotope ratios in magmatic and hydrothermal oreforming environments. Chem Geol 201:337-350

60. Magnusson B, Naykki T, Hovind H, Krysell M (2003) Handbook for calculation of measurement uncertainty, 2nd edn. Nordtest, Espoo

61. De Laeter JR, Jeffery PM (1965) The isotopic composition of terrestrial and meteoritic tin. J Geophys Res 12:2895-2903

62. De Laeter JR, Jeffery PM (1967) Tin: its isotopic and elemental abundance. Geochim Cosmochim Acta 31:969-985

63. De Laeter JR, McCulloch MT, Rosman KJR (1974) Mass spectrometric isotope dilution analyses of tin in stony meteorites and standard rocks. Earth Planet Sci Lett 22:226-232

64. Rosman KJR, Loss RD, De Laeter JR (1984) The isotopic composition of tin. Int J Mass Spectrom 56:281-291

65. McNaughton NJ, Rosman KJR (1991) Tin isotopic fractionation in terrestrial cassiterites. Geochem Cosmochem Acta 55:499-504

66. Yi W, Halliday AN, Lee DC, Christensen JN (1995) Indium and tin in basalts, sulfides, and the mantle. Geochim Cosmochim Acta 59:5081-5090

67. Hernández C, Fernández M, Quejido AJ, Sánchez DM, Morante R, Martín R (2006) Isotope dilution-thermal ionization mass spectrometry for tin in a fly ash material. Anal Chim Acta 571:279-287

68. Patton TL, Penrose WR (1989) Fission product tin in sediments. J Environ Radioact 10:201-211

69. Gale NH (1997) The isotopic composition of tin in some ancient metals and the recycling problem in metal provenancing. Archaeometry 39:31-38 